\title{
Partial redundancy in the synthesis of the D-arabinose incorporated in the cell wall arabinan of Corynebacterineae
}

\begin{abstract}
Correspondence
Christine Houssin christine.houssin@igmors. u-psud.fr
\end{abstract}

Received 4 January 2008 Revised 21 March 2008 Accepted 21 April 2008

\author{
Xavier Meniche, ${ }^{1}$ Célia de Sousa-d'Auria, ${ }^{2,3}$ Bénoit Van-der-Rest, ${ }^{1} \dagger$ \\ Suresh Bhamidi, ${ }^{4}$ Emilie Huc, ${ }^{1}$ Hairong Huang, ${ }^{4}$ Diane De Paepe, ${ }^{1}$ \\ Marielle Tropis, ${ }^{1}$ Mike McNeil, ${ }^{4}$ Mamadou Daffé ${ }^{1}$ and Christine Houssin ${ }^{2,3}$ \\ ${ }^{1}$ Université Toulouse III (Université Paul Sabatier) et Centre National de la Recherche Scientifique \\ (CNRS), Institut de Pharmacologie et Biologie Structurale (UMR 5089), Département \\ "Mécanismes Moléculaires des Infections Mycobactériennes", 205 route de Narbonne, \\ F-31077 Toulouse cedex 04, France \\ ${ }^{2}$ Institut de Génétique et Microbiologie, Université Paris-Sud, F-91405 Orsay, France \\ ${ }^{3}$ Centre National de la Recherche Scientifique, F-91405 Orsay, France \\ ${ }^{4}$ Department of Microbiology, Immunology and Pathology, Colorado State University, Fort Collins, \\ CO 80523-1682, USA
}

The major cell wall carbohydrate of Corynebacterineae is arabinogalactan (AG), a branched polysaccharide that is essential for the physiology of these bacteria. Decaprenylphosphoryl-Darabinose (DPA), the lipid donor of D-arabinofuranosyl residues of $A G$, is synthesized through a series of unique biosynthetic steps, the last one being the epimerization of decaprenylphosphoryl$\beta$-D-ribose (DPR) into DPA, which is believed to proceed via a sequential oxidation-reduction mechanism. Two proteins from Mycobacterium tuberculosis (Rv3790 and Rv3791) have been shown to catalyse this epimerization in an in vitro system. The present study addressed the exact function of these proteins through the inactivation of the corresponding orthologues in Corynebacterium glutamicum (NCgl0187 and NCgl0186, respectively) and the analysis of their in vivo effects on AG biosynthesis. We showed that NCgl0187 is essential, whereas NCgl0186 is not. Deletion of $\mathrm{NCg} / 0186$ led to a mutant possessing an AG that contained half the arabinose and rhamnose, and less corynomycolates linked to AG but more trehalose mycolates, compared with the parental strain. A candidate gene that may encode a protein functionally similar to NCgl0186 was identified in both C. glutamicum (NCg/1429) and M. tuberculosis (Rv2073c). While the deletion of NCg/1429 had no effect on AG biosynthesis of the mutant, the gene could complement the mycolate defect of the AG of the NCg/0186 mutant, strongly supporting the concept that the two proteins play a similar function in vivo. Consistent with this, the NCg/1429 gene appeared to be essential in the NCg/0186-inactivated mutant. A detailed bioinformatics analysis showed that NCgl1429, NCgl0186, Rv3791 and Rv2073c could constitute, with 52 other proteins belonging to the actinomycetales, a group of closely related short-chain reductases/dehydrogenases (SDRs) with atypical motifs. We propose that the epimerization of DPR to DPA involves three enzymes that catalyse two distinct steps, each being essential for the viability of the bacterial cells.

tPresent address: École Nationale Supérieure Agronomique de Toulouse, Avenue de l'Agrobiopole, BP 32607 Auzeville-Tolosane, F-31326 CastanetTolosan cedex, France.

Abbreviations: AG, arabinogalactan; Ara, arabinose; Araf, arabinofuranosyl; DPA, decaprenylphosphoryl-D-arabinose; DPPR, decaprenyl-monophosphoryl5-phosphoribose; DPR, decaprenyl-monophosphoryl-D-ribose; Gal, galactose; mAGP, mycolyl-arabinogalactan-peptidoglycan; PAD, pulsed amperometric detector; ppRp, 5-phosphoribofuranose pyrophosphate; Rha, rhamnose; SDR, short-chain dehydrogenase/reductase; Suc, sucrose; TDCM, trehalose dicorynomycolate; TFA, trifluoroacetic acid; TMCM, trehalose monocorynomycolate.

Two supplementary tables, listing the primers used in this study and the orthologous group of proteins obtained by computational analysis using protein sequence alignments of strains examined in this study, are available with the online version of this paper. 


\section{INTRODUCTION}

The Corynebacterineae is a suprageneric actinomycetes group that includes the causative agents of the human diseases tuberculosis, leprosy and diphtheria, Mycobacterium tuberculosis, Mycobacterium leprae and Corynebacterium diphtheriae, respectively. The cell wall core of these bacteria is made up of an unusual matrix composed of a cross-linked peptidoglycan covalently bound to arabinogalactan (AG) chains, which in turn are linked to mycolic acids, allowing the attached lipids to form the inner leaflet of an outer membrane. This complex is often referred to as mycolyl-arabinogalactan-peptidoglycan (or mAGP) complex (Daffé \& Draper, 1998).

Structural motifs of the AG polymer were first established for M. tuberculosis (Daffé et al., 1990). However, except for some variations in glycosyl linkage compositions, notably in the arabinosyl portion, the major structural features of AG are conserved among all Corynebacterineae examined so far (Daffé et al., 1993). In mycobacteria the polysaccharide is composed of two distinct regions: a homogalactan portion, composed of alternating 5-linked and 6 -linked $\beta$-galactofuranosyl residues (Daffé et al., 1990, 1993), which is covalently linked to the peptidoglycan via a disaccharide phosphate (McNeil et al., 1990), and arabinan chains, formed from arabinofuranosyl (Araf) residues, attached to carbon 5 of some of the 6-linked galactosyl (Gal) residues (Daffé et al., 1990) at their reducing termini (Besra et al., 1995) and esterified with mycolic acids at their non-reducing termini (McNeil et al., 1991). In addition to galactose $(\mathrm{Gal})$ and arabinose (Ara), rhamnose (Rha) is also found in AG of Corynebacterium glutamicum (Alderwick et al., 2005; Gebhardt et al., 2007).

In the last few years an increasing number of studies have shown that $C$. glutamicum constitutes a good model for investigating biosynthetic pathways of specific cell wall compounds of Corynebacterineae, such as mycolic acids and AG. Indeed, while these components are essential for the viability of mycobacteria, C. glutamicum mutants either totally or severely deprived of mycolates or synthesizing a truncated AG devoid of the arabinan domain are viable, although they grow slowly (Alderwick et al., 2005, 2006b; Portevin et al., 2004, 2005; Tropis et al., 2005).

The synthesis of the arabinan domain of AG results from the sequential addition of Araf residues to the galactan domain by specialized arabinosyltransferases such as Embs (Alderwick et al., 2005; Escuyer et al., 2001), AftA (Alderwick et al., 2006b) and AftB (Seidel et al., 2007). These enzymes utilize the unusual sugar donor decaprenylphosphoryl-D-arabinose (DPA) (Alderwick et al., 2005; Wolucka et al., 1994; Xin et al., 1997), which has been shown to be the only donor for the Araf residues in both mycobacteria and corynebacteria. It has been demonstrated recently that DPA is synthesized from phosphoribose diphosphate (pRpp) (Scherman et al., 1996) through an unusual series of three successive reactions (Mikusova et al., 2005): (i) transfer of pRpp to decaprenyl phosphate to form decaprenylphosphoryl-5-phosphoribose (DPPR); (ii) removal of the $5^{\prime}$ phosphate giving decaprenylphosphoryl ribose (DPR); and (iii) epimerization of DPR to DPA, which likely occurs via a sequential oxidation-reduction mechanism involving an intermediate (DPX), product of DPR oxidation and precursor of DPA (Fig. 1). Although not unambiguously identified, DPX is probably a decaprenylphosphoryl-2-keto- $\beta$-D-erythro-pentofuranose.

The only enzyme identified in the DPA biosynthesis pathway by gene inactivation and mutant analysis is the DPPR synthase, the product of the essential $M$. tuberculosis gene $R v 3806 c$ (Huang et al., 2005), and named UbiA in $C$. glutamicum (Alderwick et al., 2005). Inactivation of $u b i A$ in this bacterium produces a mutant totally devoid of arabinan (Alderwick et al., 2005). Very recently, on the basis of the similarity with proteins implicated in the arabinosylation of the Azorhizobium caulinodans nodulation factor, Mikusova et al. (2005) have proposed that $M$. tuberculosis genes $R v 3790$ and Rv3791, which are both annotated as probable oxidoreductases, could encode the two enzymes expected to be involved in the epimerization of DPR into DPA. The two genes have been cloned and expressed in Escherichia coli, and the corresponding proteins purified. The use of an in vitro assay has shown that the presence of both proteins is required to transform DPR to DPA, suggesting that the two proteins work in concert to catalyse the epimerization. It was thus interesting to address the question of the precise role of these enzymes in the biosynthesis of AG in vivo. As Rv3790 and $R v 3791$ are presumably essential in M. tuberculosis (Sassetti et al., 2003) we attempted to delete their $C$. glutamicum orthologues, NCgl0187 and NCgl0186, respectively, and characterize the resulting AG modifications.

\section{METHODS}

Strains and culture conditions. C. glutamicum (ATCC 13032 RES167) (Dusch et al., 1999) was cultured on Brain Heart Infusion (BHI) medium (Difco) at $30{ }^{\circ} \mathrm{C}$. E. coli DH5 $\alpha$ and Top 10 (Invitrogen) were used for the construction of plasmids and were grown on Luria-Bertani (LB) medium (Difco) at $37^{\circ} \mathrm{C}$. Ampicillin, kanamycin $(\mathrm{Km})$, chloramphenicol $(\mathrm{Cm})$ and sucrose (Suc) were added when required at final concentrations of $10,25,30 \mu \mathrm{g} \mathrm{ml}^{-1}$ and $10 \%(\mathrm{w} / \mathrm{v})$ (for E. coli), or $6 \mu \mathrm{g} \mathrm{ml} \mathrm{m}^{-1}$ and $10 \%(\mathrm{w} / \mathrm{v})$ (for $C$. glutamicum), respectively. Transformation of C. glutamicum by electroporation was performed as described by Bonamy et al. (1990).

DNA manipulations. C. glutamicum chromosomal DNA was extracted as described by Ausubel et al. (1987). Oligonucleotide primers were synthesized by Genosys. All DNA sequencing was carried out by Cogenics.

Construction of plasmids and strains. In order to delete NCgl0186 or NCgl0187, we used the strategy described by Schafer et al. (1994). In brief, two DNA fragments overlapping the gene to be deleted at its $5^{\prime}$ and $3^{\prime}$ extremities were amplified by PCR from C. glutamicum total DNA by using appropriate primers (186-1/186-2 and 186-3/186-4 for NCgl0186, and 187-1/187-2 and 187-3/187-4 for NCgl0187; see Supplementary Table S1) and cloned in the non-replicative vector pK18mobSac. The resulting plasmids (pK18mobsac $\Delta 186$ and 

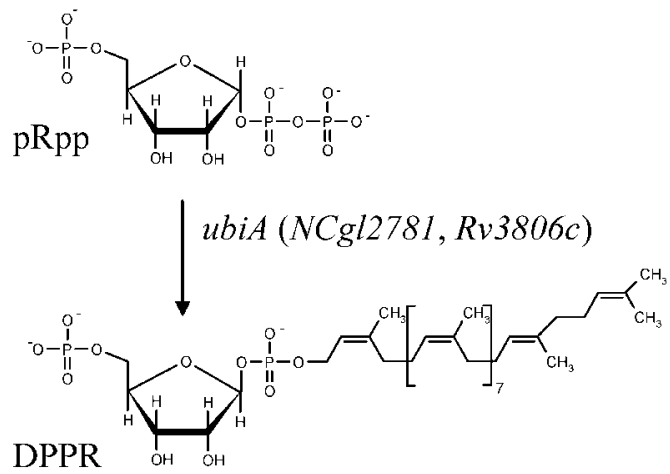

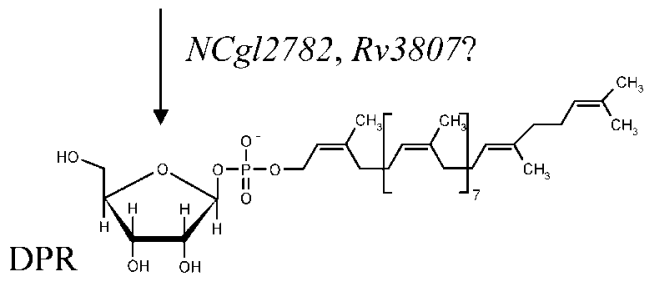

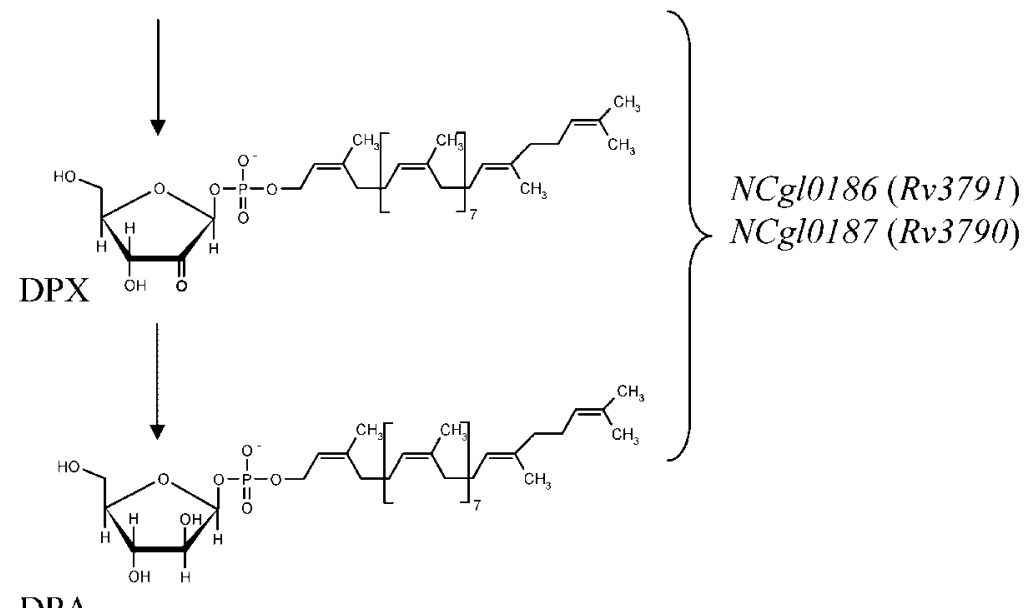

Fig. 1. The biosynthetic pathway proposed for DPA synthesis from pRpp (Mikusova et al., 2005). The isoprenoid moiety is drawn to conform to the structure of decaprenyl phosphate identified in mycobacteria. The structure of the corynebacterial equivalent is not known. Although the structure of DPX is not known with certainty, this intermediate is very likely a decaprenylphosphoryl-2-keto- $\beta$-D-erythropentofuranose. The role of $\mathrm{NCgl} 2782$ (Rv3807c) in the dephosphorylation step is putative and arises from the position of the gene on the chromosome, just beside ubiA $(R v 3806 c)$, and from its annotation as a phosphatase.

pK18mobsac $\Delta 187)$ were sequenced and independently transferred into C. glutamicum ATCC 13032 RES167 by electroporation. Transformants in which the construct was integrated into the chromosome by single crossing over were selected on BHI plates containing $\mathrm{Km}$. The second crossover event was selected by plating $\mathrm{Km}^{\mathrm{R}}$ clones on BHI plates containing Suc. $\mathrm{Km}^{\mathrm{S}}$ and $\mathrm{Suc}^{\mathrm{R}}$ colonies were screened by PCR for the correct deletion of the gene using primers binding upstream and downstream of the NCgl0186 sequence. After verification of PCR products by sequencing, one strain carrying the $\mathrm{NCgl0186}$ deletion $(\mathrm{Cg}-\Delta 186)$ was selected for further studies.

Construction of a mutant strain carrying a deletion of the NCgl0187 gene was not successful. We thus tried to inactivate this gene. For this purpose, an internal fragment was amplified using primers $187-5$ and 187-6 (see Supplementary Table S1) and cloned into plasmid pCR 2.1-TOPO using the TOPO TA cloning kit (Invitrogen) to give plasmid TOPO:: 187. This plasmid was used to electrotransform the ATCC 13032 RES167 strain. No transformant carrying the correct plasmid integration could be detected after selection on BHI plates containing $\mathrm{Km}$ and PCR analysis.

Deletion of the NCgl1429 gene was done using a strategy described previously (Portevin et al., 2004). In brief, two DNA fragments overlapping the NCgl1429 gene at its $5^{\prime}$ and $3^{\prime}$ extremities were amplified by PCR from C. glutamicum total DNA using primers 1429AMXho/1429-AMsac and 1429-AVSac/1429-AVBgl, respectively (Supplementary Table S1). These fragments were inserted flanking a $\mathrm{km}$ resistance cassette into plasmid pMCS5 (MoBiTec). The resulting plasmid was transferred into C. glutamicum ATCC 13032 RES167 by electroporation, and transformants were selected on plates containing $\mathrm{Km}$. Transformants in which allelic replacement had occurred were selected by PCR analysis using combinations of primers binding upstream and downstream of $N C g l 1429$ and in the aphIII sequences. After sequencing of the PCR products, one strain $(\mathrm{Cg}-\Delta 1429)$ was selected for further studies.

For inactivation of $N C g l 1429$ in $C g-\Delta 186$, two plasmids were constructed. First, an internal fragment was amplified using primers 1429-1 and 1429-2 (see Supplementary Table S1) and cloned into plasmid pCR2.1-TOPO to give plasmid TOPO::1429. Then, a fragment corresponding to the entire $N C g l 0186$ ORF under the $\operatorname{csp} B$ promoter was amplified from plasmid pCGL2330 (see below), digested with HindIII and SpeI, and ligated to TOPO : : 1429 digested with the same restriction enzymes. The resulting plasmids, TOPO::1429-cspB186 and TOPO::1429, were both used to electrotransform strain $\mathrm{Cg}-\Delta 186$, and transformants were selected 
on BHI plates containing Km. Genomic DNAs from mutants were analysed by three PCR amplifications using two primers binding upstream of the $5^{\prime}$ end and downstream of the $3^{\prime}$ end of the NCgl1429 gene, and the M13 forward and reverse primers binding in the pCR2.1-TOPO vector. The PCR products corresponding to the gene disruption borders were systematically sequenced.

Expression vectors encoding NCg10186 (pCGL2330), Rv3791 (pCGL2331) and NCgl1429 (pCGL2333) were constructed using pCGL482 (Peyret et al., 1993) as the cloning vector. We chose to clone these three ORFs under the control of the $\operatorname{csp} B$ promoter (Peyret et al., 1993). Coding sequences from C. glutamicum ATCC 13032 chromosomal DNA were amplified by PCR using primer pairs 1873/186-7 for NCgl0186 and 1429-3/1429-4 for NCgl1429. The Rv3791 ORF was amplified using primers $3791-1$ and $3791-2$ from the pSTblue1-Rv3791 plasmid (Mikusova et al., 2005). A DNA fragment containing the $\operatorname{csp} B$ promoter was generated using primers pcspBBam and pcspBNco and pCGL824 (Peyret et al., 1993) as template DNA. All the amplicons were digested with the appropriate restriction endonucleases (see Supplementary Table S1). Plasmids were obtained by simultaneous ligation of fragments containing the $\operatorname{csp} B$ promoter, fragments containing one ORF and the appropriately digested pCGL482. Transformants were selected on Cm-containing plates.

AG preparation. Cell walls were prepared as described previously (Daffé et al., 1990). Briefly, wet cells were resuspended in PBS buffer $(50 \mathrm{mM}, \mathrm{pH} 7.2)$ at the concentration of $5 \mathrm{~g}$ in $20 \mathrm{ml}$ and broken in a cell disrupter $\left(2.7 \times 10^{8} \mathrm{~Pa}\right)$. After three cell disrupter cycles, intact cells were removed by centrifugation $(3000 \mathrm{~g})$ and the supernatant containing the cell walls was then centrifuged $(27000 \mathrm{~g}, 1 \mathrm{~h})$. The resulting cell wall pellet was treated with aqueous $2 \%(\mathrm{w} / \mathrm{v})$ SDS at $95{ }^{\circ} \mathrm{C}$ for $1 \mathrm{~h}$ and sedimented again at $27000 \mathrm{~g}$. This was followed by two acetone washes and the pellet thus obtained was mAGP. mAGP was further treated with $2 \mathrm{M} \mathrm{NaOH}$ and stirred gently at $80{ }^{\circ} \mathrm{C}$ for $16 \mathrm{~h}$ to remove the mycolic acid residues and cleave peptidoglycan to solubilize AG. The pellet was discarded and the $\mathrm{pH}$ of the supernatant was adjusted to 7.0 with glacial acetic acid. This neutralized AG was dialysed for at least 3-4 h with three 11 changes of MilliQ water. The AG obtained was concentrated by rotary evaporation to a final volume of $1 \mathrm{ml}$, and was freeze-dried and stored till further use.

Enzymic treatments of soluble AG. The soluble AG was treated with partially purified endogenous arabinase (Dong et al., 2006) at $37{ }^{\circ} \mathrm{C}$ for $12 \mathrm{~h}$, followed by extraction with $\mathrm{CHCl}_{3} / \mathrm{CH}_{3} \mathrm{OH} / \mathrm{H}_{2} \mathrm{O}$ $(10: 10: 3$, by vol.). After centrifugation, the supernatant, which contained most of the released arabinans, was used for MALDI-TOF MS analysis.

To further elucidate the cell wall AG configuration, the soluble AG was treated with Cellulomonas arabinase obtained as described previously (McNeil et al., 1994), which specifically releases Ara2 and Ara4 from AG.

Analysis of AG. The glycosyl composition of purified cell walls was determined by hydrolysing an aliquot of mAGP with $2 \mathrm{M}$ trifluoroacetic acid (TFA) for $2 \mathrm{~h}$ at $110{ }^{\circ} \mathrm{C}$, followed by trimethylsilylation (Sweeley et al., 1963) and GC analysis of the resulting products, or by alditol acetate formation, as described previously (Daffé et al., 1990).

HPLC analysis of soluble AG samples treated with arabinase was carried out on a Dionex system equipped with a CarboPac PA1 analytical column $(4 \times 250 \mathrm{~mm})$. Total run time was $50 \mathrm{~min}$, the $\mathrm{NaOH}$ concentration $(100 \mathrm{mM})$ being consistent throughout. Sodium acetate concentration was varied from 0 to $450 \mathrm{mM}$ for a period of $50 \mathrm{~min}$. The eluted samples were detected using a pulsed amperometric detector (PAD).
For MALDI-TOF MS analysis, samples were peracetylated with acetic anhydride $(100 \mu \mathrm{l})$ in the presence of pyridine $(100 \mu \mathrm{l})$ at room temperature overnight and recovered after removal of the solvent in chloroform prior to MALDI-TOF MS. The acetylated AG samples were run in positive ion reflector mode on a Bruker Ultraflex MALDITOF/TOF mass spectrometer (Bruker Daltonics). One microlitre of the sample was mixed with $1 \mu \mathrm{l}$ matrix $\left(10 \mathrm{mg} \mathrm{ml}^{-1}\right.$ dihydroxybenzoic acid in $50 \%$ acetonitrile/0.1\% TFA) and allowed to air dry on the MALDI target plate.

For ${ }^{1} \mathrm{H}$ - and ${ }^{13} \mathrm{C}$-NMR analysis, AGs were solubilized in ${ }^{2} \mathrm{H}_{2} \mathrm{O}(20 \mathrm{mg}$ in $0.5 \mathrm{ml}$ ) and analysed at 600 and $150.9 \mathrm{MHz}$, respectively, on a Bruker Avance $600 \mathrm{MHz}$ NMR spectrometer equipped with a TCI cryoprobe. ${ }^{1} \mathrm{H}$-decoupled ${ }^{13} \mathrm{C}$ spectra were obtained with a DEPT 135 pulse sequence in a DQD acquisition mode.

Extraction and quantification of corynomycolic acids. Lipids were extracted from wet cells for $16 \mathrm{~h}$ with $\mathrm{CHCl}_{3} / \mathrm{CH}_{3} \mathrm{OH}(1: 2, \mathrm{v} / \mathrm{v})$ at room temperature; the cells were re-extracted with $\mathrm{CHCl}_{3} / \mathrm{CH}_{3} \mathrm{OH}$ $(1: 1, \mathrm{v} / \mathrm{v})$ and $\mathrm{CHCl}_{3} / \mathrm{CH}_{3} \mathrm{OH}(2: 1, \mathrm{v} / \mathrm{v})$ for $16 \mathrm{~h}$. The three organic phases were pooled and concentrated by means of rotary evaporation. The crude lipid extracts were partitioned between the aqueous and the organic phases arising from a mixture of $\mathrm{CHCl}_{3} / \mathrm{H}_{2} \mathrm{O}(1: 1, \mathrm{v} / \mathrm{v})$. The lower organic phases were collected and evaporated to dryness to yield the crude lipid extracts from each strain. Subsequently, they were examined comparatively using TLC on silica gel-coated plates (Durasil-25, $0.25 \mathrm{~mm}$ thickness, Macherey-Nagel) developed with $\mathrm{CHCl}_{3} / \mathrm{CH}_{3} \mathrm{OH} / \mathrm{H}_{2} \mathrm{O}$ (30:8:1 or $65: 25: 4$, by vol.). Glycolipids were detected by spraying plates with $0.2 \%$ anthrone in concentrated $\mathrm{H}_{2} \mathrm{SO}_{4}$, followed by heating. The corynomycolate content of extractable lipids was determined in three independent experiments as follows. Lipid extracts $(100 \mathrm{mg})$ of the various strains were dried under vacuum and saponified (Daffé et al., 1983); the saponified products were acidified with $20 \% \mathrm{H}_{2} \mathrm{SO}_{4}$. The resulting fatty acids were extracted with diethyl ether, washed with water, converted to methyl esters with diazomethane and dried under vacuum, and weighed. The fatty acid methyl esters were separated from contamination on a silica gel column irrigated with different concentrations of diethyl ether in petroleum ether $(0,5,10,20$ and $100 \%, v / v)$. Fractions were analysed by TLC developed with $\mathrm{CH}_{2} \mathrm{Cl}_{2}$. Lipids were detected by spraying plates with rhodamine $\mathrm{B}$ and fractions containing corynomycolates were pooled and weighed. The AG-bound mycolic acids present in the delipidated cells, i.e. the material after the $\mathrm{CHCl}_{3} / \mathrm{CH}_{3} \mathrm{OH}$ extraction (described above), were saponified with $40 \% \mathrm{KOH}$ in 2-methoxyethanol $(1: 7, \mathrm{v} / \mathrm{v})$ at $110{ }^{\circ} \mathrm{C}$ for $3 \mathrm{~h}$ (Daffé et al., 1983) and the solution was neutralized using $20 \% \mathrm{H}_{2} \mathrm{SO}_{4}$. The released mycolic acids were extracted with diethyl ether and methylated with diazomethane. The resulting fatty acid methyl esters were examined using TLC on silica gel-coated plates developed as described above. When significant amounts of fatty acids other than mycolic acids were present in the saponification products, corynomycolates were isolated by chromatography on a silica gel column as described above and weighed.

Epimerase assay. The cell wall or cell membrane $(70 \mu \mathrm{l}, 5.5 \mathrm{mg}$ protein $\left.\mathrm{ml}^{-1}\right), 10 \mathrm{mM}$ ATP $(1 \mu \mathrm{l}), 10 \mathrm{mM}$ each of FAD, NAD and NADP $\left(3 \mu \mathrm{l}\right.$ each), and $\left[{ }^{14} \mathrm{C}\right]$ pRpp $\left(20 \mu \mathrm{l}, 10000\right.$ c.p.m. $\left.\mu \mathrm{l}^{-1}\right)$ were added to MOPS buffer ( $\mathrm{pH} 8$ with $\mathrm{MgCl}_{2}$ ) to give a final volume of $160 \mu$ l. The reaction mixture was incubated for $90 \mathrm{~min}$ at $37^{\circ} \mathrm{C}$. Subsequently, the mixture was extracted with $\mathrm{CHCl}_{3} / \mathrm{CH}_{3} \mathrm{OH} / \mathrm{H}_{2} \mathrm{O}$ $(8: 4: 3$, by vol.), centrifuged briefly at $4500 \mathrm{~g}$, and the organic layer was separated and dried. This was subjected to TFA ( $2 \mathrm{M})$ hydrolysis for $1 \mathrm{~h}$ at $110{ }^{\circ} \mathrm{C}$, cooled, dried down in $\mathrm{CH}_{3} \mathrm{OH}$ and analysed for Ara and ribose content by HPLC. The samples (neutral sugars after TFA hydrolysis) were analysed using a Carbopac PA01 analytical column $(4 \times 250 \mathrm{~mm})$. The sugars were separated with an isocratic solvent system consisting of $10 \% \mathrm{NaOH}(100 \mathrm{mM})$ in water for $45 \mathrm{~min}$. The 
${ }^{14} \mathrm{C}$-containing components were detected using a Beta ram detector. The same HPLC system was connected to a PAD to detect nonradioactive standards of the respective sugars for comparative quantification.

\section{RESULTS}

\section{Genomic comparison of the 3790-3791 locus}

Data from Mikusova et al. (2005) strongly suggest that in M. tuberculosis the products of Rv3790 and Rv3791 work in concert to catalyse the conversion of DPR to DPA. Rv3790 and $R v 3791$ are located upstream of the genes encoding the arabinosyltransferases AftA, EmbA, EmbB and EmbC (Fig. 2). All these genes are part of a large cell wall biosynthesis cluster containing, among others, Rv3806c, which encodes the enzyme involved in the first step of DPA synthesis, the transfer of a 5-phosphoribosyl residue from pRpp to decaprenyl phosphate to form DPPR (Huang et al., 2005). An in silico analysis revealed that orthologues of $R v 3790$ and $R v 3791$ are present in all the available genome sequences of Corynebacterineae. The two genes are always organized in a putative operon and, except in Corynebacterium jeikeium, are adjacent to the aftA-emb cluster (Fig. 2). In C. glutamicum, Rv3790 and 3791 orthologues correspond to genes NCgl0187 and NCgl0186, respectively. Sequence comparisons at protein level show $65 \%$ identity for Rv3790 and NCgl0187 and $57 \%$ identity for Rv3791 and NCgl0186. As Rv3790 and Rv3791 are presumably essential in M. tuberculosis (Sassetti et al., 2003), attempts were made to delete their C. glutamicum orthologues in order to address the question of the functions of the corresponding enzymes in the biosynthesis of AG in vivo, a strategy already successfully used to decipher the functions of mycobacterial essential genes (Alderwick et al., 2006a, b; Portevin et al., 2004, 2005).

\section{Construction and growth characteristics of Cg- $\Delta 186$}

In an attempt to delete either NCgl0186 or NCgl0187, nonreplicative pK18mobsac-derivative plasmids were constructed (pK18mobsac $\Delta 186$ and pK18mobsac $\Delta 187$ ), each carrying sequences adjacent to the gene to be deleted (Schafer et al., 1994). $\mathrm{Km}^{\mathrm{S}}$ and Suc ${ }^{\mathrm{R}}$ clones resulting from two recombination events between plasmid and chromosome were obtained for both deletions. In the case of NCgl0186, 50 clones were analysed by PCR and half of them were found to have a gene deletion at the expected position. In comparison to the wild-type strain, however, the $\Delta$ NCgl0186 mutant (thereafter named Cg- $\Delta 186$ ) exhibited no significant phenotypic changes, had similar growth and did not aggregate in liquid cultures. These results indicated that although $\mathrm{NCgl0186}$ may be involved in the synthesis of DPA, the mutant strain has a behaviour very different from that previously observed for the mycolate-less or AG-truncated mutants, i.e. a rough and matt colony phenotype, instead of the smooth and shiny one of the wild-type, and very slow growth and strong aggregation in liquid cultures (Alderwick et al., 2006a, b; Portevin et al., 2004, 2005).

In the case of $N C g l 0187$ about 200 clones were analysed by PCR but, unlike NCgl0186, all of the clones showed the wild-type genotype, indicating either a strong disadvantage of NCgl0187 deletion or the essentiality of the gene even in the corynebacterial host. Furthermore, even when the analysis was continued up to 3 weeks to eventually obtain slow-growing rough-textured colonies as described for $\mathrm{emb}$ and aftA mutants in C. glutamicum (Alderwick et al., 2005, 2006b), no such colonies were visible. As no deletion

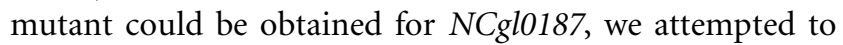
inactivate the gene by plasmid integration, but no integration mutants could be obtained by this procedure

\section{M. tuberculosis}

M. leprae

M. bovis

C. glutamicum

C. efficiens

C. diphtheriae

C. jeikeium

Nocardia farcinica

Rhodococcus sp. RHA1
$19.5 \mathrm{~kb}$
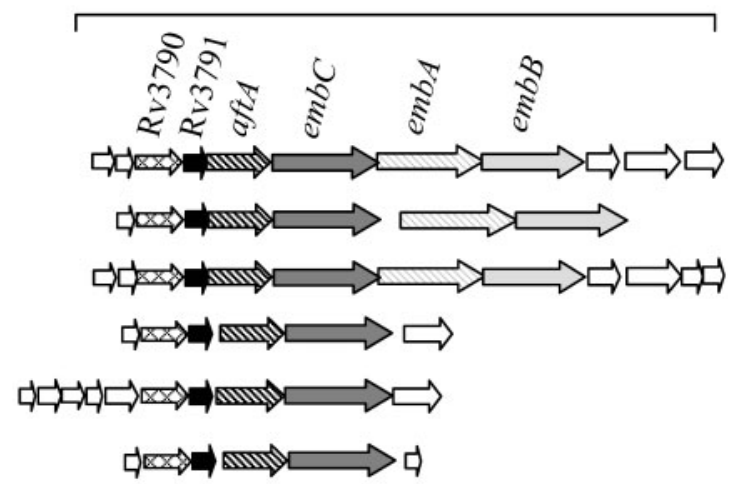

마다

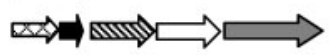

$\Rightarrow$ andy
Fig. 2. Comparison of the Rv3790/3791 locus within Corynebacterineae. In M. tuberculosis the locus contains Rv3790, Rv3791, aft $A, e m b C$, embA and embB, and five other ORFs, three of unknown function and the last two annotated fadD35 and transposase. Together these ORFs cover the genome sequence (RefSeq no. NC_000962) between positions 4234780 and 4254327 . In $C$. glutamicum the locus contains NCgl0186 (Rv3790 orthologue), NCgl0187 (Rv3791 orthologue), aft $A, \mathrm{Cg}$-emb (embC orthologue) and two ORFs of unknown functions. These ORFs cover the genome sequence (RefSeq no. NC_003450) between positions 201757 and $21 \overline{1} 759$. 
either. We thus concluded that $N C g l 0187$ is likely an essential gene.

\section{Glycosyl compositional analysis of the cell wall and AG from Cg- $\triangle 186$ and ATCC 13032 strains}

Purified cell walls from $\mathrm{Cg}-\Delta 186$ and its parental ATCC 13032 wild-type of C. glutamicum were analysed for glycosyl composition. As shown in Table $1, \mathrm{Cg}-\Delta 186$ still produced Ara but contained only half of the amount observed in the wild-type strain, resulting in a lower Ara:Gal ratio than that of the ATCC 13032 strain. A similar diminution of the Rha: Gal ratio was also observed for the mutant strain, suggesting that the rhamnosyl residues are linked to the arabinan moiety of AG. Confirmation of these data came from the analysis of AG released from the peptidoglycan using base treatment, as described previously for mycobacterial cell walls (Daffé et al., 1990), which showed a twofold decrease in the Ara: Gal and Rha: Gal ratios of the mutant when compared with those of the parental strain (data not shown). Complementation of $\mathrm{Cg}-\Delta 186$ with plasmid pCGL2330 (containing NCgl0186) or pCGL2331 (containing Rv3191) led in both cases to the restoration of a normal level of Ara (Table 1). This indicated that the mycobacterial Rv3191 protein exhibited in vivo a function similar to that of the corynebacterial NCgl0186. The Rha: Gal ratio was, however, only slightly increased ( $10 \%)$ by complementation of Cg- $\Delta 186$ with the plasmid containing NCgl0186 and unchanged by the presence of a plasmid containing Rv3791, a phenomenon likely to be due to a problem with co-regulation of the synthesis of the Rha-containing arabinan segment of AG. We thus concluded that NCgl0186 is directly or indirectly involved in the reaction of epimerization of DPR into DPA, but that another enzyme possessing a similar function is likely to be present in C. glutamicum. These data are consistent with the normal growth phenotype observed for the $\mathrm{Cg}-\Delta 186$ strain.

Table 1. Quantitative analysis of the sugar constituents of the cell walls extracted from C. glutamicum ATCC 13032, its isogenic $\Delta N C g / 0186(\mathrm{Cg}-\Delta 186)$ mutant and the mutant complemented with either the corynebacterial gene [Cg$\Delta 186(\mathrm{pCGL} 2330)]$ or its mycobacterial orthologue [Cg$\Delta 186(\mathrm{pCGL} 2331)]$

Purified cell walls were hydrolysed with acid and the resulting materials were derivatized and analysed by GC, as described in Methods. The values are the means \pm SD of at least three independent experiments.

\begin{tabular}{|lcc|}
\hline Strain & Ara : Gal & Rha : Gal \\
\hline Wild-type & $4.50 \pm 0.5$ & $1.0 \pm 0.1$ \\
Cg- $\Delta 186$ & $2.20 \pm 0.2$ & $0.56 \pm 0.05$ \\
Cg- $\Delta 186($ pCGL2330) & $4.60 \pm 0.5$ & $0.60 \pm 0.05$ \\
Cg- $\Delta 186$ (pCGL2331) & $4.30 \pm 0.3$ & $0.60 \pm 0.05$ \\
\hline
\end{tabular}

\section{In vitro epimerization of DPR into DPA by cell membrane and cell wall from $\mathrm{Cg}-\Delta 186$ and wild-type strains}

To prove the direct involvement of NCgl0186 in DPA biosynthesis in C. glutamicum we determined the effect of mutation of the coding gene on the epimerization of DPR into DPA. Thus, both membranes and cell walls prepared from Cg- $\Delta 186$ and its parental strain, ATCC 13032, were independently incubated with radioactive $p\left[{ }^{14} \mathrm{C}\right] \mathrm{Rpp}$ and decaprenyl phosphate. The resulting mixtures of DP $\left[{ }^{14} \mathrm{C}\right] \mathrm{R}$ and $\mathrm{DP}\left[{ }^{14} \mathrm{C}\right] \mathrm{A}$ were hydrolysed and the radioactive sugars released were analysed by HPLC. The epimerization of DPR into DPA was observed when wild-type cell membranes and, to a lesser extent, wild-type cell walls were used as enzyme sources (Table 2). When the experiments were done with $\mathrm{Cg}-\Delta 186$ cell walls and cell membranes we observed a $50 \%$ decrease in the DPA formed as compared with the wild-type. This change was partially restored by complementation with NCgl0186. Overexpression of NCgl0186 in the wild-type bacterium did not lead to increased epimerization (Table 2), probably due to the fact that NCgl0186 was not limiting for epimerization in the wild-type bacterium. These data established the direct involvement of NCgl0186 in the epimerization of DPR into DPA and confirmed the contribution of another enzyme with similar function.

\section{Structural analysis of the AG from the cell walls of $\mathrm{Cg}-\Delta 186$ and wild-type strains}

In order to investigate the potential effects of NCgl0186 deletion on the structure of AG we performed different types of analysis. First, the soluble AG from $\mathrm{Cg}-\Delta 186$ and wild-type were treated with an arabinase partially purified from Mycobacterium smegmatis (Dong et al., 2006), and the reaction products were analysed by MALDI-TOF MS. Similar fragments were observed in the degradative products of the AG from the wild-type and $\mathrm{Cg}-\Delta 186$ strains; they were composed of oligomers of Ara of up to nine residues. Second, the soluble AGs from both strains were treated with a mixture of arabinases and galactofuranases from Cellulomonas (McNeil et al., 1994), and analysed by HPLC and MALDI-TOF MS. Again, no significant difference could be detected between the patterns obtained from Cg- $\Delta 186$ and ATCC 13032 strains by this method (data not shown). Consistent with these observations, the glycosyl-linkage compositions of the AG from the wild-type and mutant strains of C. glutamicum were very similar to one another and to those of other strains of the species (Alderwick et al., 2005; Gebhardt et al., 2007). Finally, since ${ }^{13} \mathrm{C}$-NMR spectroscopy of AGs has proven to be an appropriate tool for comparative qualitative analysis of AGs, AG from the two isogenic strains was compared by this technique (Daffé et al., 1990, 1993; Gebhardt et al., 2007). The ${ }^{13} \mathrm{C}-\mathrm{NMR}$ spectra obtained from Cg- $\Delta 186$ and ATCC 13032 were superimposable (data not shown) and identical to that published 
previously for another strain of C. glutamicum (Gebhardt et al., 2007). We thus concluded that the AGs from the two strains were composed of the same structural motifs.

\section{Lipid analysis of the $\mathrm{Cg}-\Delta 186$ and wild-type strains}

In view of the decrease in the Ara content of the AG from $\mathrm{Cg}-\Delta 186$, we reasoned that this might affect the lipid profile of the mutant, notably the amount of corynomycolates linked to AG. Accordingly, we performed a comparative lipid analysis of $\mathrm{Cg}-\Delta 186$ and the wild-type strain, focusing on corynomycolate-containing compounds, i.e. cell wall and trehalose monocorynomycolate (TMCM) and trehalose dicorynomycolate (TDCM) (Puech et al., 2001). Cells were labelled with acetate and the lipids were extracted with organic solvents. Analysis of the extractable lipids by TLC and quantification of the corynomycolate esterifying trehalose showed that the mutant strain accumulated $57 \%$ more corynomycolates than did the parent strain (Table 3). Concomitantly, the Cg- $\Delta 186$ strain contained $40 \%$ less corynomycolates covalently bound to AG (Table 3 ). These data showed that NCgl0186 deletion affected the tethering of corynomycolates to AG, probably through the reduction of the number of sites of attachment of these lipids. Consistent with this finding, this phenotype was completely reversed in the mutant strain complemented with either pCGL2330 (containing NCgl0186) or pCGL2331 (containing Rv3191). We thus concluded that $\mathrm{Cg}-\Delta 186$ elaborated an AG with fewer Ara units and corynomycoloyl residues but with structural motifs qualitatively similar to those of the parental strain.

Table 2. Epimerization of DPR to DPA by cell membranes and cell walls of C. glutamicum ATCC 13032, its isogenic $\triangle \mathrm{NCgl0186}(\mathrm{Cg}-\Delta 186)$ mutant and the complemented mutant $\mathrm{Cg}-\Delta 186$ (pCGL2330), and the wild-type strain in which NCgl0186 was overexpressed [ATCC 13032(pCGL2330)]

Epimerase activity was assayed by measuring the ability of cell wall or cell membrane extracts to transform pRpp into DPA. The percentages of Ara and ribose were determined relative to the sum of the two sugars present in the isolated mixture. The values are the means $\pm S D$ of at least three independent experiments.

\begin{tabular}{|c|c|c|c|c|}
\hline \multirow[t]{2}{*}{ Strain } & \multicolumn{2}{|c|}{$\begin{array}{c}\text { Cell wall as } \\
\text { enzyme source }\end{array}$} & \multicolumn{2}{|c|}{$\begin{array}{l}\text { Cell membrane } \\
\text { as enzyme } \\
\text { source }\end{array}$} \\
\hline & $\begin{array}{l}\text { Ara } \\
(\%)\end{array}$ & $\begin{array}{c}\text { Ribose } \\
(\%)\end{array}$ & $\begin{array}{l}\text { Ara } \\
(\%)\end{array}$ & $\begin{array}{c}\text { Ribose } \\
(\%)\end{array}$ \\
\hline ATCC 13032 & $72 \pm 4$ & $28 \pm 4$ & $83 \pm 2$ & $17 \pm 3$ \\
\hline$C g-\Delta 186$ & $41 \pm 3$ & $59 \pm 3$ & $51 \pm 3$ & $49 \pm 3$ \\
\hline Cg- $\Delta 186($ pCGL2330) & $44 \pm 3$ & $56 \pm 3$ & $63 \pm 4$ & $37 \pm 4$ \\
\hline ATCC 13032(pCGL2330) & $62 \pm 2$ & $38 \pm 2$ & $78 \pm 3$ & $22 \pm 3$ \\
\hline
\end{tabular}

Table 3. Quantitative analysis of cell wall-linked and extractable corynomycolates from C. glutamicum ATCC 13032, its isogenic mutant $\Delta \mathrm{NCgl0186}(\mathrm{Cg}-\Delta 186)$ and the mutant complemented with either the corynebacterial gene $[\mathrm{Cg}$ $\Delta 186(\mathrm{pCGL} 2330)]$ or its mycobacterial orthologue [Cg$\Delta 186($ pCGL2331)]

The percentages of corynomycolates in cell walls and extractable lipids were determined relative to the masses of the delipidated cells and extractable lipids, respectively. The values are the means $\pm \mathrm{SD}$ of at least three independent experiments. Corynomycolates were isolated by saponification of the delipidated cells and extractable lipids, purified by chromatography and weighed, as described in Methods.

\begin{tabular}{|lcc|}
\hline Strain & $\begin{array}{c}\text { Wall-linked coryno- } \\
\text { mycolates }(\%)\end{array}$ & $\begin{array}{c}\text { Corynomycolates } \\
\text { in extractable } \\
\text { lipids }(\%)\end{array}$ \\
\hline ATCC 13032 & $1.0 \pm 0.1$ & $33 \pm 2$ \\
Cg- $\Delta 186$ & $0.6 \pm 0.1$ & $52 \pm 3$ \\
Cg- $\Delta 186$ (pCGL2330) & $1.1 \pm 0.1$ & $29 \pm 2$ \\
Cg- $\Delta 186$ (pCGL2331) & $1.0 \pm 0.1$ & $28 \pm 2$ \\
\hline
\end{tabular}

\section{Search for an NCgl0186 orthologue and construction of the corresponding mutant}

As DPA has been shown to be the only donor of Ara in $C$. glutamicum (Alderwick et al., 2005), these results indicated that DPA is still produced by the $\mathrm{Cg}-\Delta 186$ mutant, as confirmed by enzyme assay (Table 2). As a consequence, the occurrence of Ara in the mutant could be explained by the redundancy of $\mathrm{NCgl0186}$ in C. glutamicum or, alternatively, NCgl0186 could have a function in corynebacteria different from that of Rv3791 in mycobacteria, despite the homology and the similar genomic environment of the two genes, i.e. Rv3791 and NCgl0186. However the last hypothesis seems unlikely in view of our data that show that the expression of Rv3791 is able to complement the deficit of $\mathrm{Cg}-\Delta 186$ in Ara. In order to identify genes encoding one or more proteins functionally equivalent to NCgl0186 in C. glutamicum, BLAST searches were performed against this genome using $\mathrm{NCgl0186}$ as a query sequence (Altschul et al., 1990). On the basis of the score values, only one sequence, the product of the NCgl1429 gene, could be considered to encode a paralogous protein. This protein shows $35 \%$ identity with NCgl0186 (Fig. 3). We checked for the occurrence of an NCgl1429 orthologue in the M. tuberculosis genome and found Rv2073c. As shown in Fig. 3 amino acid alignments of NCgl1429 and Rv2073c with NCgl0186 and Rv3791 revealed well-conserved blocks, and led us to propose NCgl1429 as the protein possessing a functional redundancy with NCg10186. It should be noted that, in contrast to NCg10186, no paralogue was found for NCgl0187 in C. glutamicum. We thus attempted to delete NCgl1429 both in ATCC 13032 and in Cg- $\Delta 186$.

A $\mathrm{km}$ resistance cassette flanked by arms about $500 \mathrm{bp}$ identical to the $5^{\prime}$ and $3^{\prime}$ parts of $N C g l 1429$ was cloned into 


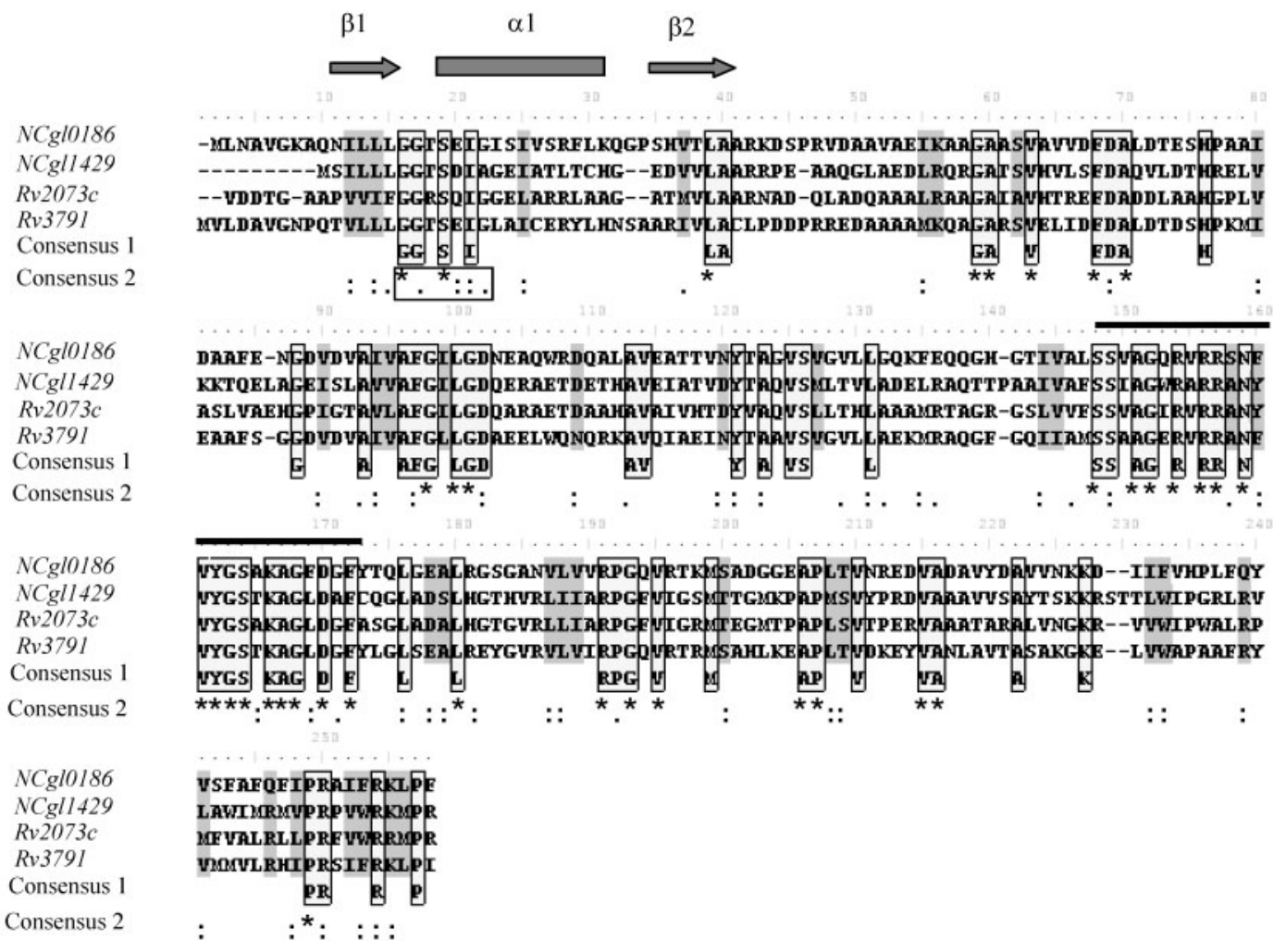

Fig. 3. Multiple alignments of protein sequences of NCgl0186, Rv3791, NCgl1429, Rv2073c and the deduced consensus sequence (consensus 1). Identical residues are boxed and similar amino acids have light-grey backgrounds. The line above the sequence indicates the conserved block chosen for computational analysis. The first three secondary elements predicted from the NCgl0186 sequence are shown. Consensus 2 corresponds to the consensus sequence obtained from CLUSTAL W alignments of all the orthologues found in Corynebacterineae given in Supplementary Table S2, except for MAP1819c of M. paratuberculosis, which was not considered for the end of the alignment owing to its length (187 residues). Boxed residues in consensus 2 correspond to a conserved motif that may be involved in cofactor binding.

a vector unable to replicate in corynebacteria. This construct was transferred into both $C$. glutamicum ATCC 13032 and $\mathrm{Cg}-\Delta 186$. In both cases $\mathrm{km}^{R}$ transformants were obtained and analysed by PCR using various combinations of primers. From the wild-type strain one clone $(\mathrm{Cg}$ $\Delta 1429)$ among 20 gave the amplification pattern consistent with allelic replacement of $\mathrm{NCgl1429}$ with the $\mathrm{km}$ cassette. This exchange was the result of two recombination events. In the $\mathrm{Cg}-\Delta 186$ host only the first recombination event, corresponding to plasmid integration, could be obtained, as revealed by the analysis of 200 clones. This absence of deletions led us to suspect that, as for NCgl0187, inactivation of both genes (i.e. NCgl0186 and NCgl1429) was not possible because of the essentiality of the function associated with the two proteins in the epimerization of DPR to DPA. To conclusively demonstrate this hypothesis we tried to inactivate $N C g l 1429$ in $\mathrm{Cg}-\Delta 186$ by plasmid integration in the presence or absence of a functional copy of NCgl0186. For that purpose a pCR2.1-TOPO plasmid derivative containing an $\sim 500$ bp NCgl1429 internal fragment was first constructed (TOPO:: 1429). We then transferred a copy of NCgl0186 under the control of the $\operatorname{csp} B$ promoter into this plasmid (TOPO :: 1429-cspB186). No integration mutants could be obtained when Cg- $\Delta 186$ was transformed with TOPO::1429, while integration took place very easily when TOPO :: 1429-cspB186 was used as integration vector. These data demonstrated that NCgl1429 is essential in the absence of NCgl0186.

\section{Analysis of the NCgl1429 mutant strain}

Cell walls from Cg- $\Delta 1429$ were analysed for glycosyl composition and corynomycolate content as described for Cg- $\Delta 186$ and ATCC 13032. Surprisingly, and in sharp contrast with Cg- $\Delta 186$, no change in the Ara:Gal and Rha: Gal ratios could be detected in the mutant strain, compared with the wild-type. Likewise, no significant difference was observed in terms of amounts of extractable and bound corynomycolates of the mutant, compared with the parental ATCC 13032 strain. These results strongly suggest that in the presence of a functional NCgl0186, NCgl1429 has no detectable contribution in vivo. Based on the data obtained previously with the partially redundant mycoloyltransferases of M. tuberculosis (Puech et al., 2002), 
we tested the in vivo effect of NCgl1429 overexpression on the epimerization reaction in the absence of NCg10186. For that purpose, a plasmid containing the NCgl1429 ORF under the control of the strong promoter of $\operatorname{csp} B$ was constructed (pCGL2333) and introduced into the Cg- $\Delta 186$ strain. As we have shown that the quantification of corynomycolates linked to $A G$ reasonably reflects the complementation of the phenotype of the $\mathrm{Cg}-\Delta 186$ mutant (Table 3), we performed a quantitative analysis of the cell wall corynomycolates of Cg- $\Delta 186$ (pCGL2333). The percentage of cell wall-linked corynomycolates of $\mathrm{Cg}$ $\Delta 186$ (pCGL2333) was found to be $1 \%( \pm 0.1)$, a value close to that obtained with the wild-type strain and with the Cg- $\Delta 186$ strain complemented with either NCgl0186 or Rv3791 (Table 3). This result indicated that overexpression of NCgl1429 in vivo could restore the defect in AG produced by the absence of $\mathrm{NCgl0186}$, thus pointing to a partial redundancy of the two enzymes similar to that demonstrated for the three mycoloyltransferases of $M$. tuberculosis (Puech et al., 2002).

\section{Conservation and redundancy of NCgl0186 orthologous proteins among Corynebacterineae}

NCgl0186, NCgl1429, Rv3791 and Rv2073c belong to the superfamily of short chain dehydrogenases/reductases (SDRs), which contains enzymes catalysing $\operatorname{NAD}(\mathrm{P})(\mathrm{H})-$ dependent oxido-reduction (Jornvall et al., 1995; Oppermann et al., 2003). This is a large and functionally heterogeneous protein family with low sequence identities but with conserved motifs and common structural organization. In bacteria the number of SDR members deduced from genome analysis varies considerably from one organism to another, but it should be noted that this number is especially large in $M$. tuberculosis ( 57 members) (Jornvall et al., 1999). We wanted to evaluate the level of sequence conservation and of redundancy of NCgl0186 orthologues among the Corynebacterineae. For this purpose, one of the conserved blocks, SSxAGxRxRRxNxVYGSxKAGD (shown in Fig. 3), was chosen. It contains the three conserved residues of the catalytic active triad (S, $\mathrm{Y}$ and $\mathrm{K}$ ) characteristic of SDR proteins (Oppermann et al., 2003). This motif was searched for in the NCBI Reference Sequence (RefSeq) collection (http://www.ncbi.nlm.nih. gov/RefSeq/). Forty-seven sequences were found to match with this motif totally and six more with one mismatch. Pair-wise alignments showed that 52 of the 53 sequences possessed between 36 and $100 \%$ identities with Rv3791 and thus can be considered to be closely related. All these protein sequences belong to Actinomycetales, mostly to Corynebacterineae (see Supplementary Table S2). This analysis shows that all members of Corynebacterineae for which the genome sequence is known possess at least one, and the great majority two, orthologous genes.

The SDR superfamily is divided into five families on the basis of protein length and specific sequence motifs. According to their length (between 242 and 260 aa, except for MAP1819c from Mycobacterium paratuberculosis, which has only 187 residues) the proteins identified in this work are classical SDRs. CLUSTAL W alignment (Fig. 3) and secondary structure predictions performed on these protein sequences allowed the identification of only two SDR motifs specific to the classical family among the seven proposed by Kallberg et al. (2002) (Table 4). In particular, the typical pattern of three Gly residues (TGxxxGxG) in the $\mathrm{N}$-terminal domain characteristic of the $\operatorname{NAD}(\mathrm{P})(\mathrm{H})$ binding site is missing. Nevertheless, a conserved motif, GG/AxSxxG/A, localized in the $\beta 1-\alpha 1$ predicted structure that resembles the patterns of both intermediate SDRs (G/ AxxGxxG/A) and divergent SDRs (GxxxxxSxA), could constitute an atypical dinucleotide-binding motif (Fig. 3, Table 4).

\section{DISCUSSION}

The mAGP complex, which constitutes the cell wall skeleton of the very singular cell envelope of Corynebacterineae, represents, with mycolic acids, the hallmark of all the members of this group of bacteria (Besra et al., 1995; Daffé, 2005; Dover et al., 2004; McNeil et al., 1991). Despite the physiological importance of this complex, its biosynthesis is far from being totally understood, mostly because of its essentiality for the viability of M. tuberculosis. However, thanks to the use of C. glutamicum as a model organism for Corynebacterineae, significant progress on understanding AG biosynthesis has been made recently, in particular with the discovery of new glycosyltransferases (Alderwick et al., 2006b; Seidel et al., 2007). As AG is made up of D-arabinofuranosyl and

Table 4. Conserved motifs in the NCgl0186 orthologue group and comparison with classical SDR motifs

Secondary structure elements were predicted using PredictProtein (Rost et al., 2004). In the motif, 'a' denotes an aromatic residue, ' $h$ ' a hydrophobic residue and ' $x$ ' any residue. Alternative amino acids at a motif position are given within brackets.

\begin{tabular}{|lccl|}
\hline Secondary structure element & Classical SDR motif & NCgl0186 orthologue group motif & \multicolumn{1}{c|}{ Suggested function $^{\star}$} \\
\hline$\beta 1+\alpha 1$ & TGxxGhaG & G[GA]xSx[EDQ][IM][GA] & Structural role in cofactor-binding region \\
$\beta 3+\alpha 3$ & DAx[DV] & [DEN]Ax[DV] & Binding of coenzyme \\
$\alpha 5$ & Yx[AS][ST]K & YGS[AT]K & Part of active site \\
\hline
\end{tabular}

${ }^{\star}$ Persson et al. (2003). 
D-galactofuranosyl units, which are both rare sugars (McNeil et al., 1987), a complete understanding of their biosynthethic pathways could provide suitable targets for new chemotherapeutics. Ara is produced from DPA, the formation of which in mycobacteria has been shown to proceed by an unusual epimerization reaction that occurs when the sugar is linked to a prenyl phosphate (Mikusova et al., 2005). Previous experiments performed with purified recombinant $\operatorname{Rv} 3790$ and $\operatorname{Rv3791}$ proteins from $M$. tuberculosis have shown that DPR could be converted into DPA in an in vitro system when both proteins were present in the reaction mixtures (Mikusova et al., 2005). Despite the fact that Rv3790 and Rv3791 were sufficient to catalyse the epimerization of DPR in vitro, there is no indication that, in a physiological context, other proteins are not also involved in this reaction. To investigate the in vivo functions of these proteins in the biosynthesis of AG, we deliberately chose to inactivate their orthologues NCgl0186 and NCgl0187 in C. glutamicum. This strategy was based on the fact that, unlike mycobacteria, corynebacteria can survive with a truncated AG totally devoid of the arabinan domain (Alderwick et al., 2005), and because of the synteny observed for the $3790 / 3791$ locus from genome analysis of numerous Corynebacterineae, suggesting conserved functions for the orthologous proteins.

While the deletion of NCgl0186 was very easy to achieve, all our attempts to delete NCgl0187 were unsuccessful, probably reflecting the essentiality of this gene. The earlier generation of a ubiA mutant in C. glutamicum and its analysis has shown that DPA is the only Ara donor for AG biosynthesis and, as a consequence, its total absence leads to the production of a galactan instead of an AG (Alderwick et al., 2005, 2006a). Cg- $\Delta 186$ showed a different pattern: the strain possesses an AG with the same structural motifs as the wild-type strain but contains a significantly reduced quantity of arabinosyl residues. The fact that arabinan was reduced but not totally absent demonstrated a role for NCgl0186 in DPA synthesis, but either in a way different from that observed for Rv3791 in vitro or with functional redundancy in C. glutamicum. The first hypothesis is unlikely for two reasons. First, a direct involvement of $\mathrm{NCgl0186}$ in DPR epimerization was verified by in vitro experiments. Second, a normal level of Ara was restored by in vivo Rv3791 expression in Cg$\Delta 186$. An in silico search for paralogues of NCgl0186 revealed only one gene, NCgl1429, which is conserved among all Corynebacterineae except $M$. leprae and Mycobacterium bovis species. Although the genetic organization around NCgl1429 or its orthologues differs from one species to another, the gene of interest is always in close proximity, and likely in some cases in an operon together with genes encoding proteins predicted to be involved in precorrin biosynthesis. As in the case of NCgl0186, deletion of NCgl1429 was very easy to realize in the wild-type strain but, in contrast to $\mathrm{Cg}-\Delta 186$, the resulting mutant synthesized an AG with an Ara: Gal ratio identical to that of the wild-type strain. However, the hypothesis that NCgl1429 is involved in DPA synthesis is strongly supported by the following observations. (i) NCgl1429 could be inactivated in the presence of a copy of NCgl0186 but not in its absence, indicating that NCgl1429 becomes essential when NCgl0186 is absent. (ii) A total recovery of cell wall mycolates was obtained when NCgl1429 was overexpressed in the absence of NCgl0186, indicating that NCgl1429 could fully replace NCgl0186 in the epimerization reaction under these conditions. We thus propose that epimerization of DPR into DPA involves three enzymes that catalyse two distinct steps, each being essential for the viability of the cell. One step would be catalysed by $\mathrm{NCgl0187}$ and another by NCgl0186; in the absence of the latter enzyme, the reaction would be catalysed by NCgl1429. Although it has been shown previously that epimerization results from DPR oxidation followed by reduction to DPA (Mikusova et al., 2005), we were not able to dissect the two steps by identifying which enzyme is responsible of the oxidation reaction and which catalyses the reduction reaction.

By deleting NCgl0186 we obtained, for what is believed to be the first time, a mutant in which the DPA synthesis is lowered, allowing us to determine the influence of DPA level on AG biosynthesis in vivo. Considering the significant diminution of Rha and corynomycolates observed for the $\mathrm{Cg}-\Delta 186$ mutant and the occurrence of similar structural motifs in the mutant and the wild-type in our structural analyses of AG, it seems that a decrease in DPA synthesis leads to a decrease in the number of branching arabinan chains rather than in the length of these chains. These results suggest that changes in the level of DPA could influence the number of priming sites for Araf deposition to the galactan core but not (or to a lesser extent) Ara polymerization.

The essentiality of the epimerization step was unexpected as the inactivation of the gene encoding the first enzyme involved in DPA synthesis, the DPPR synthase (UbiA), in C. glutamicum, produced a viable mutant (Alderwick et al., 2005). One possible reason is that absence of epimerization leads to a continued synthesis of DPR, which in turn significantly affects the pool of decaprenyl phosphate, so that this becomes limiting for peptidoglycan synthesis and lethal for the cell. This hypothesis has to be proven experimentally.

Apparent redundancy of gene function appears to be common among genes involved in a wide range of physiological processes. This redundancy has been found for some enzymes involved in cell wall biosynthesis in Corynebacterineae, such as mycoloyltransferases in corynebacteria (Brand et al., 2003; De Sousa-D'Auria et al., 2003) and mycobacteria (Puech et al., 2002), and Embs in mycobacteria (Escuyer et al., 2001). It could also be the case for the enzyme that dephosphorylates DPPR to DPR. This phosphatase is believed to be encoded by the gene located directly upstream of ubiA (Rv3807c in $M$. tuberculosis and NCgl2782 in C. glutamicum). Preliminary 
experiments with an NCgl2782 mutant of C. glutamicum indicate that if this gene is effectively the phosphatase, a redundant enzyme must exist, as in the case of NCgl0186. In agreement with this, in silico analysis showed a paralogue (NCgl2785) located very close to NCgl2782. Further experiments will be needed to determine the precise role of the enzymic redundancies observed in the synthesis of DPA and more generally in cell wall compound biosynthesis.

\section{ACKNOWLEDGEMENTS}

We are grateful to Dr Anne Lemassu for her valuable assistance in NMR spectroscopy. This work was supported by the Centre National de la Recherche Scientifique (CNRS, France) and by National Institutes of Health (NIH, USA), National Institute of Allergy and Infectious Diseases (NIAID), grant AI37706 to M.M. The NMR spectrometers were financed by the CNRS, the University Paul Sabatier, the Région Midi-Pyrénées, and the European Structural Funds (FEDER).

\section{REFERENCES}

Alderwick, L. J., Radmacher, E., Seidel, M., Gande, R., Hitchen, P. G., Dell, A., Sahm, H., Eggeling, L. \& Besra, G. S. (2005). Deletion of $\mathrm{Cg}$ emb in Corynebacterineae leads to a novel truncated cell wall arabinogalactan, whereas inactivation of $\mathrm{Cg}$-ubiA results in an arabinan deficient mutant with a cell wall galactan core. J Biol Chem 280, 32362-32371.

Alderwick, L. J., Dover, L. G., Seidel, M., Gande, R., Sahm, H., Eggeling, L. \& Besra, G. S. (2006a). Arabinan deficient mutants of Corynebacterium glutamicum and the consequent flux in decaprenylmonophosphoryl-D-arabinose metabolism. Glycobiology $\mathbf{1 6}$ 1073-1081.

Alderwick, L. J., Seidel, M., Sahm, H., Besra, G. S. \& Eggeling, L. (2006b). Identification of a novel arabinofuranosyl transferase (AftA) involved in cell wall arabinan biosynthesis in Mycobacterium tuberculosis. J Biol Chem 281, 15653-15661.

Altschul, S. F., Gish, W., Miller, W., Myers, E. W. \& Lipman, D. J. (1990). Basic local alignment search tool. J Mol Biol 215, 403-410.

Ausubel, F. M., Brent, R., Kingston, R. E., Moore, D. D., Seidman, J. G., Smith, J. A. \& Struhl, K. (1987). Current Protocols in Molecular Biology. New York: Wiley.

Besra, G. S., Khoo, K. H., McNeil, M. R., Dell, A., Morris, H. R. \& Brennan, P. J. (1995). A new interpretation of the structure of the mycolyl-arabinogalactan complex of Mycobacterium tuberculosis as revealed through characterization of oligoglycosylalditol fragments by fast-atom bombardment mass spectrometry and ${ }^{1} \mathrm{H}$ nuclear magnetic resonance spectroscopy. Biochemistry 34, 4257-4266.

Bonamy, C., Guyonvarch, A., Reyes, O., David, F. \& Leblon, G. (1990). Interspecies electro-transformation in Corynebacteria. FEMS Microbiol Lett 54, 263-269.

Brand, S., Niehaus, K., Puhler, A. \& Kalinowski, J. (2003). Identification and functional analysis of six mycolyltransferase genes of Corynebacterium glutamicum ATCC 13032: the genes cop1, cmt1, and $c m t 2$ can replace each other in the synthesis of trehalose dicorynomycolate, a component of the mycolic acid layer of the cell envelope. Arch Microbiol 180, 33-44.

Daffé, M. (2005). The cell envelope of corynebacteria. In Handbook of Corynebacterium glutamicum, pp. 121-148. Edited by L. Eggeling \& M. Bott. Boca Raton, FL: CRC Press.
Daffé, M. \& Draper, P. (1998). The envelope layers of mycobacteria with reference to their pathogenicity. Adv Microb Physiol 39, 131-203.

Daffé, M., Lanéelle, M. A., Asselineau, C., Levy-Febrault, V. \& David, H. (1983). Intérêt taxonomique des acides gras des mycobactéries: proposition d'une méthode d'analyse. Ann Microbiol (Paris) 134, 241-256 (in French).

Daffé, M., Brennan, P. J. \& McNeil, M. (1990). Predominant structural features of the cell wall arabinogalactan of Mycobacterium tuberculosis as revealed through characterization of oligoglycosyl alditol fragments by gas chromatography/mass spectrometry and by ${ }^{1} \mathrm{H}$ and ${ }^{13} \mathrm{C}$ NMR analyses. J Biol Chem 265, 6734-6743.

Daffé, M., McNeil, M. \& Brennan, P. J. (1993). Major structural features of the cell wall arabinogalactans of Mycobacterium, Rhodococcus, and Nocardia spp. Carbohydr Res 249, 383-398.

De Sousa-D'Auria, C., Kacem, R., Puech, V., Tropis, M., Leblon, G., Houssin, C. \& Daffé, M. (2003). New insights into the biogenesis of the cell envelope of corynebacteria: identification and functional characterization of five new mycoloyltransferase genes in Corynebacterium glutamicum. FEMS Microbiol Lett 224, 35-44.

Dong, X., Bhamidi, S., Scherman, M., Xin, Y. \& McNeil, M. R. (2006). Development of a quantitative assay for mycobacterial endogenous arabinase and ensuing studies of arabinase levels and arabinan metabolism in Mycobacterium smegmatis. Appl Environ Microbiol 72, 2601-2605.

Dover, L. G., Cerdeno-Tarraga, A. M., Pallen, M. J., Parkhill, J. \& Besra, G. S. (2004). Comparative cell wall core biosynthesis in the mycolated pathogens, Mycobacterium tuberculosis and Corynebacterium diphtheriae. FEMS Microbiol Rev 28, 225-250.

Dusch, N., Puhler, A. \& Kalinowski, J. (1999). Expression of the Corynebacterium glutamicum panD gene encoding L-aspartate- $\alpha$ decarboxylase leads to pantothenate overproduction in Escherichia coli. Appl Environ Microbiol 65, 1530-1539.

Escuyer, V. E., Lety, M. A., Torrelles, J. B., Khoo, K. H., Tang, J. B., Rithner, C. D., Frehel, C., McNeil, M. R., Brennan, P. J. \& Chatterjee, D. (2001). The role of the $e m b A$ and $e m b B$ gene products in the biosynthesis of the terminal hexaarabinofuranosyl motif of Mycobacterium smegmatis arabinogalactan. J Biol Chem 276, 48854-48862.

Gebhardt, H., Meniche, X., Tropis, M., Kramer, R., Daffé, M. \& Morbach, S. (2007). The key role of the mycolic acid content in the functionality of the cell wall permeability barrier in Corynebacterineae. Microbiology 153, 1424-1434.

Huang, H., Scherman, M. S., D’Haeze, W., Vereecke, D., Holsters, M., Crick, D. C. \& McNeil, M. R. (2005). Identification and active expression of the Mycobacterium tuberculosis gene encoding 5-phospho- $\alpha$-D-ribose-1-diphosphate: decaprenyl-phosphate 5-phosphoribosyltransferase, the first enzyme committed to decaprenylphosphoryl-D-arabinose synthesis. J Biol Chem 280, 24539-24543.

Jornvall, H., Persson, B., Krook, M., Atrian, S., Gonzalez-Duarte, R., Jeffery, J. \& Ghosh, D. (1995). Short-chain dehydrogenases/reductases (SDR). Biochemistry 34, 6003-6013.

Jornvall, H., Hoog, J. O. \& Persson, B. (1999). SDR and MDR: completed genome sequences show these protein families to be large, of old origin, and of complex nature. FEBS Lett 445, 261-264.

Kallberg, Y., Oppermann, U., Jornvall, H. \& Persson, B. (2002). Short-chain dehydrogenases/reductases (SDRs). Eur J Biochem 269, 4409-4417.

McNeil, M., Wallner, S. J., Hunter, S. W. \& Brennan, P. J. (1987). Demonstration that the galactosyl and arabinosyl residues in the cellwall arabinogalactan of Mycobacterium leprae and Mycobacterium tuberculosis are furanoid. Carbohydr Res 166, 299-308. 
McNeil, M., Daffé, M. \& Brennan, P. J. (1990). Evidence for the nature of the link between the arabinogalactan and peptidoglycan of mycobacterial cell walls. J Biol Chem 265, 18200-18206.

McNeil, M., Daffé, M. \& Brennan, P. J. (1991). Location of the mycolyl ester substituents in the cell walls of mycobacteria. J Biol Chem 266, 13217-13223.

McNeil, M. R., Robuck, K. G., Harter, M. \& Brennan, P. J. (1994). Enzymatic evidence for the presence of a critical terminal hexaarabinoside in the cell walls of Mycobacterium tuberculosis. Glycobiology 4, 165-173.

Mikusova, K., Huang, H., Yagi, T., Holsters, M., Vereecke, D., D'Haeze, W., Scherman, M. S., Brennan, P. J., McNeil, M. R. \& Crick, D. C. (2005). Decaprenylphosphoryl arabinofuranose, the donor of the D-arabinofuranosyl residues of mycobacterial arabinan, is formed via a two-step epimerization of decaprenylphosphoryl ribose. J Bacteriol 187, 8020-8025.

Oppermann, U., Filling, C., Hult, M., Shafqat, N., Wu, X., Lindh, M., Shafqat, J., Nordling, E., Kallberg, Y. \& other authors (2003). Shortchain dehydrogenases/reductases (SDR): the 2002 update. Chem Biol Interact 143-144, 247-253.

Persson, B., Kallberg, Y., Oppermann, U. \& Jornvall, H. (2003). Coenzyme-based functional assignments of short-chain dehydrogenases/reductases (SDRs). Chem Biol Interact 143-144, 271-278.

Peyret, J. L., Bayan, N., Joliff, G., Gulik-Krzywicki, T., Mathieu, L., Schechter, E. \& Leblon, G. (1993). Characterization of the $\operatorname{csp} B$ gene encoding PS2, an ordered surface-layer protein in Corynebacterium glutamicum. Mol Microbiol 9, 97-109.

Portevin, D., De Sousa-D’Auria, C., Houssin, C., Grimaldi, C., Chami, M., Daffé, M. \& Guilhot, C. (2004). A polyketide synthase catalyzes the last condensation step of mycolic acid biosynthesis in mycobacteria and related organisms. Proc Natl Acad Sci U S A 101, 314-319.

Portevin, D., de Sousa-D’Auria, C., Montrozier, H., Houssin, C., Stella, A., Lanéelle, M. A., Bardou, F., Guilhot, C. \& Daffé, M. (2005). The acyl-AMP ligase FadD32 and AccD4-containing acyl-CoA carboxylase are required for the synthesis of mycolic acids and essential for mycobacterial growth: identification of the carboxylation product and determination of the acyl-CoA carboxylase components. J Biol Chem 280, 8862-8874.

Puech, V., Chami, M., Lemassu, A., Lanéelle, M. A., Schiffler, B., Gounon, P., Bayan, N., Benz, R. \& Daffé, M. (2001). Structure of the cell envelope of corynebacteria: importance of the non-covalently bound lipids in the formation of the cell wall permeability barrier and fracture plane. Microbiology 147, 1365-1382.
Puech, V., Guilhot, C., Perez, E., Tropis, M., Armitige, L. Y., Gicquel, B. \& Daffé, M. (2002). Evidence for a partial redundancy of the fibronectin-binding proteins for the transfer of mycoloyl residues onto the cell wall arabinogalactan termini of Mycobacterium tuberculosis. Mol Microbiol 44, 1109-1122.

Rost, B., Yachdav, G. \& Liu, J. (2004). The PredictProtein server. Nucleic Acids Res 32, (Web Server issue) W321-W326.

Sassetti, C. M., Boyd, D. H. \& Rubin, E. J. (2003). Genes required for mycobacterial growth defined by high density mutagenesis. Mol Microbiol 48, 77-84.

Schafer, A., Tauch, A., Jager, W., Kalinowski, J., Thierbach, G. \& Puhler, A. (1994). Small mobilizable multi-purpose cloning vectors derived from the Escherichia coli plasmids pK18 and pK19: selection of defined deletions in the chromosome of Corynebacterium glutamicum. Gene 145, 69-73.

Scherman, M. S., Kalbe-Bournonville, L., Bush, D., Xin, Y., Deng, L. \& McNeil, M. (1996). Polyprenylphosphate-pentoses in mycobacteria are synthesized from 5-phosphoribose pyrophosphate. J Biol Chem 271, 29652-29658.

Seidel, M., Alderwick, L. J., Birch, H. L., Sahm, H., Eggeling, L. \& Besra, G. S. (2007). Identification of a novel arabinofuranosyltransferase AftB involved in a terminal step of cell wall arabinan biosynthesis in Corynebacterineae, such as Corynebacterium glutamicum and Mycobacterium tuberculosis. J Biol Chem 282, 14729-14740.

Sweeley, C. C., Bentley, R., Makita, M. \& Wells, W. W. (1963). Gasliquid chromatography of trimethysil derivatives of sugars and related substances. J Am Chem Soc 85, 2497-2507.

Tropis, M., Meniche, X., Wolf, A., Gebhardt, H., Strelkov, S., Chami, M., Schomburg, D., Krämer, R., Morbach, S., Daffé, M. \& other authors (2005). The crucial role of trehalose and structurally related oligosaccharides in the biosynthesis and transfer of mycolic acids in Corynebacterineae. J Biol Chem 280, 26573-26585.

Wolucka, B. A., McNeil, M. R., de Hoffmann, E., Chojnacki, T. \& Brennan, P. J. (1994). Recognition of the lipid intermediate for arabinogalactan/arabinomannan biosynthesis and its relation to the mode of action of ethambutol on mycobacteria. J Biol Chem 269, 23328-23335.

Xin, Y., Lee, R. E., Scherman, M. S., Khoo, K. H., Besra, G. S., Brennan, P. J. \& McNeil, M. (1997). Characterization of the in vitro synthesized arabinan of mycobacterial cell walls. Biochim Biophys Acta $1335,231-234$.

Edited by: W. Bitter 